\title{
Fractal Interpolation in the Financial Analysis of a Company
}

\author{
Miguel Angel Leon-Ogazon ${ }^{1}$, Edna Araceli Romero-Flores ${ }^{1}$, Tomas Morales-Acoltzi ${ }^{2}$, Angel Machorro-Rodriguez ${ }^{1}$ \\ \& Marcos Salazar-Medina ${ }^{1}$ \\ ${ }^{1}$ Instituto Tecnologico de Orizaba, Mexico \\ ${ }^{2}$ Universidad Nacional Autonoma de Mexico, Mexico \\ Correspondence: Miguel Angel Leon-Ogazon, Instituto Tecnologico de Orizaba, Mexico.
}

Received: November 25, 2016

Accepted: December 20, 2016

Online Published: January 15, 2017

doi:10.5430/ijba.v8n1p80

URL: http://dx.doi.org/10.5430/ijba.v8n1p80

\begin{abstract}
This article discusses a new approach to financial analysis of a company, using the technique known as a function of fractal interpolation, to calculate missing observations in a database containing financial information about an organization. Numerical experiments were carried out to compare the effects of using traditional linear interpolation with the function of fractal interpolation, revealing that the data adjusts better to the fractal method.
\end{abstract}

Keywords: fractal, fractal interpolation, financial analysis

\section{Introduction}

The scientist Benoit Mandelbrot (1967) designated the term fractal to the irregular and fragmented forms that appear in nature, which are impossible to analyze, applying traditional Euclidean geometry.

The word fractal comes from the Latin term fractus, which means irregular or fragmented and is used to refer to objects in space or fluctuations in time that possess a form of self-similarity and cannot be described by a sole or absolute scale of measurement. Fractals are recurrently irregular through space and/or time, and have sections that are repeated like layers of an onion at different levels or scales; the parts of an object or fractal sequence are exact or static copies of the whole and by moving or stretching them, they can be matched to this (Klonowski, 2000).

According to Spinadel (2003), fractal geometry is a new mathematical theory, offering an alternative to traditional Euclidean geometry, describing geometric objects that are self-symmetrical or symmetrical in scale. This means that when these objects are amplified, their parts maintain an exact resemblance to the whole, prolonging the similarity with the parts of the parts and so on to infinity; these objects do not manifest translational symmetry, that is they lack the smoothness associated with Euclidean lines, planes and spheres, instead maintaining a rough and jagged outline, at any scale.

One of the tools offered by fractal geometry is fractal interpolation, which unlike traditional Euclidean geometry, contemplates the irregular forms and processes occurring in nature. This is why it has been applied to various fields of science for data analysis, as it appears to be better adjusted to these.

Fractal interpolation is an alternative technique that has been developed to fit data that have a fractal structure (Serpa \& Buescu, 2015). Unlike traditional interpolation, fractal interpolation adjusts to an undefined curve, so it is superior to other functions that are based on linear functions ( $\mathrm{Li} \& \mathrm{Gao}, 2014)$.

The function of fractal interpolation has been applied to diverse scientific studies, for example in the analysis of time series for a volume of data for traffic observed on a highway (Dai, Hou, \& Ye, 2016), as well as for the analysis of time series on the height of waves in order to obtain information concerning the local tendency of waves, which is essential for the management of the coasts and studies of environmental impact (Liu, Xia, Gunson, Wright, \& Arnold, 2014).

Fractal theory has been applied in the administrative context, to the study of the organization of companies (Torrés \& Goís, 2014), as well as to the analysis of business processes (van Rensburg, 2014) and production (Mulligan, 2016).

When a data analysis is performed, the problem of absence or loss of data may occur making it difficult to carry out a correct analysis. Therefore, various techniques are used to calculate the missing values such as linear interpolation. However, this method does not contemplate the irregular behavior of phenomena. 
Fractal geometry considers the irregularity of forms and phenomena present in nature, and has shown to have a better fit in the analysis of data with irregular behavior.

In this study, we used the fractal approach in the administrative context, when using the function of fractal interpolation in the analysis of financial data of a company, to calculate values missing from the database.

The present article is distributed as follows: first we present the data and methodology used to carry out this study, followed by detailed numerical experiments and finally the discussions and conclusions derived from this work.

\section{Data}

The financial information generated in these organizations is reflected in their financial statements, which is why these statements are used when undergoing financial analysis.

For the creation of the database, the financial statements from the company Gruma S.A.B. de C.V. were consulted. This is listed on the Mexican Stock Exchange and pertains to the manufacturing sector, and is thus required to submit financial statements.

The database consists of 65 observations concerning the value of the company's assets, for a period which goes from the fourth quarter of 1999 until the fourth quarter of 2015.

The asset, in compliance with International Financial Reporting Standards, is a resource controlled by the company that is related to past events, from which it expects to obtain economic benefits in the future.

\section{Methodology}

One of the problems presented in the management of databases for its analysis is the absence or loss of observations, as this situation prohibits carrying out an adequate analysis.

There are several traditional methods for calculating missing data in time series such as linear interpolation, however this work considers a contemporary approach: the fractal approach.

In order to accomplish this study, first data were normalized; then they were submitted to a test of normality, as a sign of fractality is that the data do not follow a normal distribution. Finally, the functions of linear and fractal interpolation were applied, in order to compare the results obtained when each one was used.

\section{Numerical Experiments}

\subsection{Data Normalization}

For data management, a static normalization was applied, which homogenized the values of the time series in order not to depend on the number of observations. This normalization consists of dividing each of the observations by the maximum value of the time series to obtain values between 0 and 1 .

$$
\mathrm{Vi}=\frac{\mathrm{a}_{\mathrm{i}}}{\max \mathrm{a}_{\mathrm{i}}}
$$

Where:

$\mathrm{a}_{\mathrm{i}}=$ value to be normalized

$\max a=$ Maximum value 


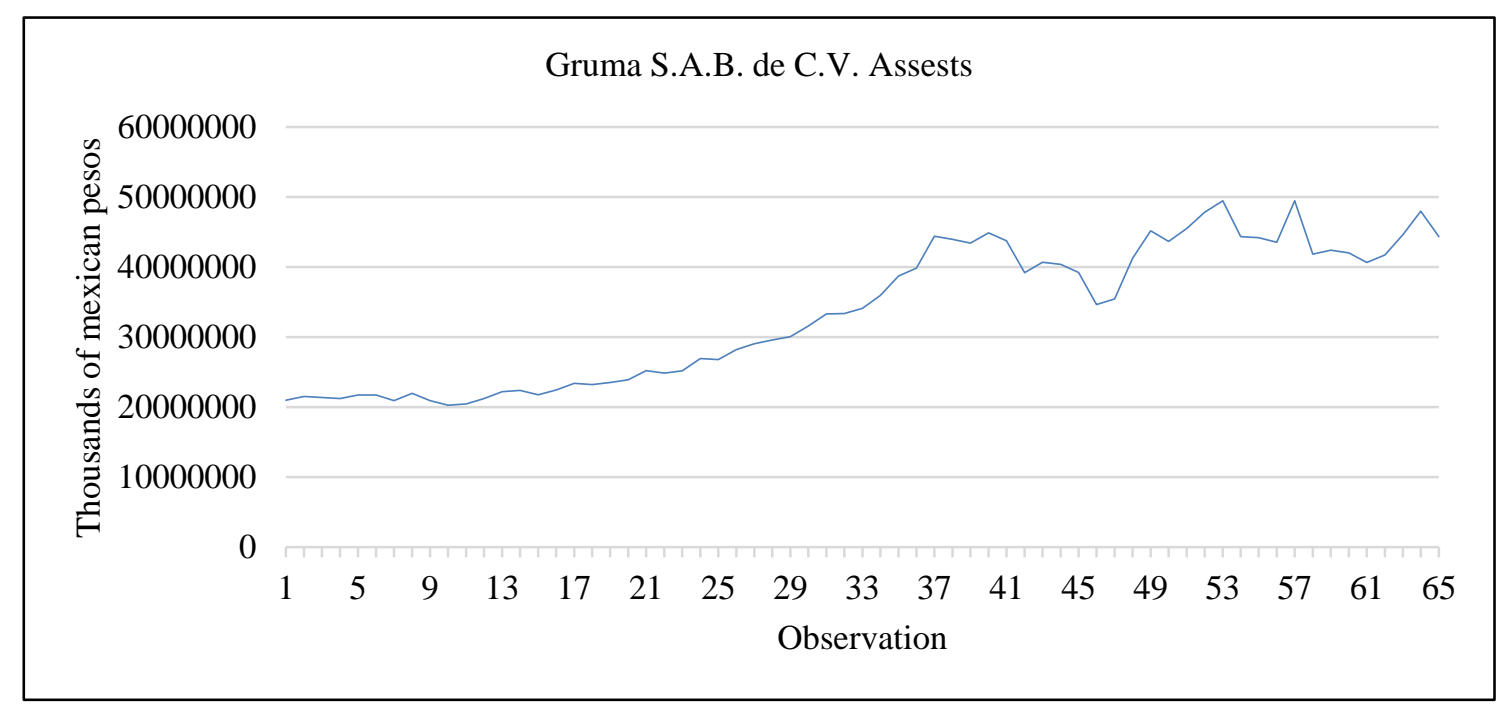

(a)

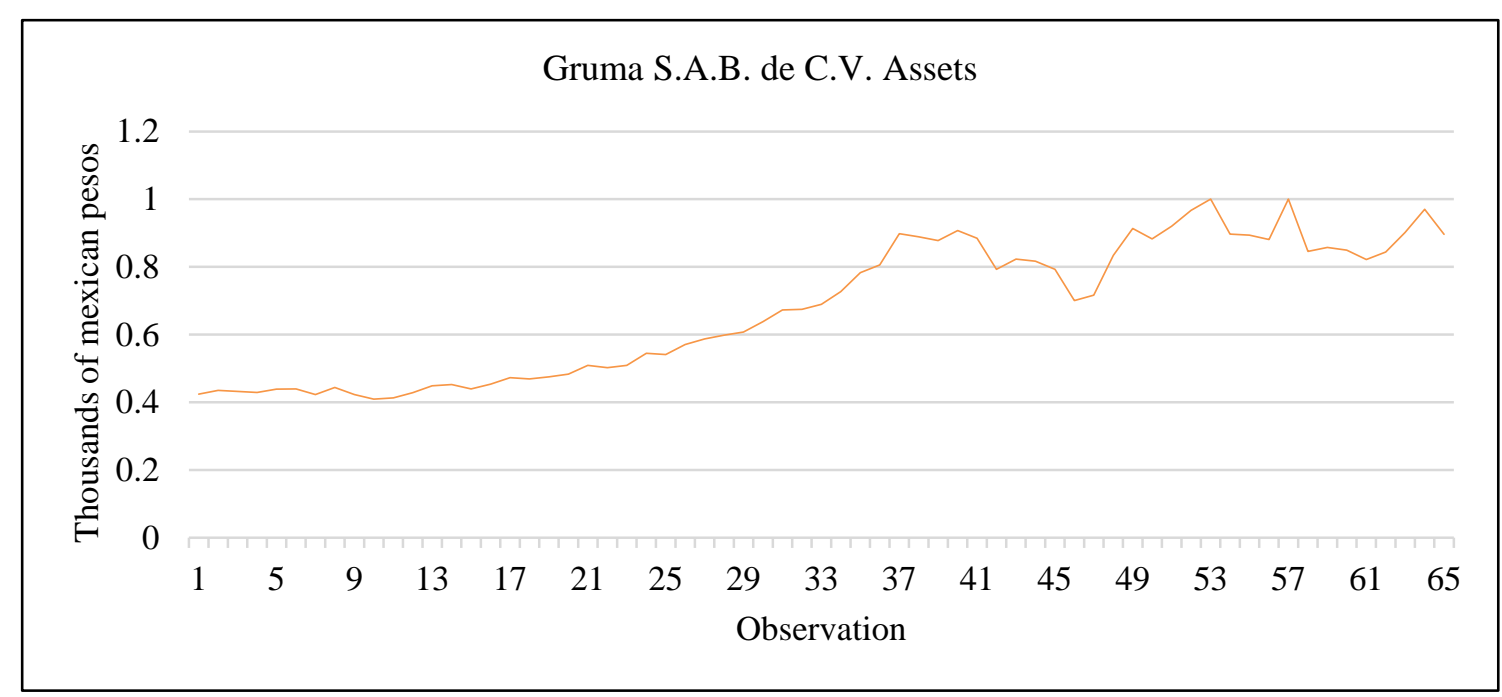

(b)

Figure 1. Original data (a) normalized data (b)

Figure 1 shows a comparison between the graph of the original time series (a) and the graph of the standard time series (b), it is apparent that this procedure does not cause changes in data behavior.

\subsection{Normality Test}

Using Mathwave EasyFit software version 5.6, a normal distribution adjustment test was performed on the time series, to check whether the data that make up the series follow this distribution or not, because one of the characteristics of the fractal is that they do not follow a normal distribution.

The Anderson-Darling statistical test was chosen to determine whether data follow a normal distribution. 
Table 1. Results from the normality of data test using Mathwave EasyFit software version 5.6

\begin{tabular}{cc}
\hline \multicolumn{2}{c}{ Anderson-Darling } \\
\hline Size of sample & 65 \\
\hline Statistics & 2.85 \\
\hline Range & 10 \\
\hline$\alpha$ & 0.05 \\
\hline Critical value & 2.5018 \\
\hline Rejected? & Yes \\
\hline
\end{tabular}

According to the results obtained by adjusting to normal distribution in the EasyFit software (shown in Table 1), the assumption that the data conform to a normal distribution must be rejected, thus indicating that the analyzed data have a fractal aspect.

\subsection{Lineal Interpolation}

The function of linear interpolation calculates the values between two points using straight lines. This function connects two given points in $\mathrm{x}_{\mathrm{i}}$, that is $\left(\mathrm{x}_{0}, \mathrm{y}_{0}\right)$ and $\left(\mathrm{x}_{1}, \mathrm{y}_{1}\right)$. To calculate any point between the values of $\mathrm{x}_{0}$ and $\mathrm{x}_{1}$ it is necessary to follow the equation for line (2) which can be derived geometrically as follows.

$$
\frac{\mathrm{y}-\mathrm{x}_{0}}{\mathrm{y}_{1}-\mathrm{y}_{0}}=\frac{\mathrm{x}-\mathrm{x}_{0}}{\mathrm{x}_{1}-\mathrm{x}_{0}}
$$

The $y$ value is unknown, so when calculating (2) it is:

$$
y=y_{0}+\left(x-x_{0}\right) \frac{y_{1}-y_{0}}{x_{1}-x_{0}}
$$

It is assumed that $\mathrm{x}_{0}<\mathrm{x}<\mathrm{x}_{1}$.

If the interpolation consists of more than two points, that is $\mathrm{N}>2$, with points $\mathrm{x}_{0}, \mathrm{x}_{1}, \ldots, \mathrm{x}_{\mathrm{N}}$, the interpolation is concatenated between pairs of continuous points.

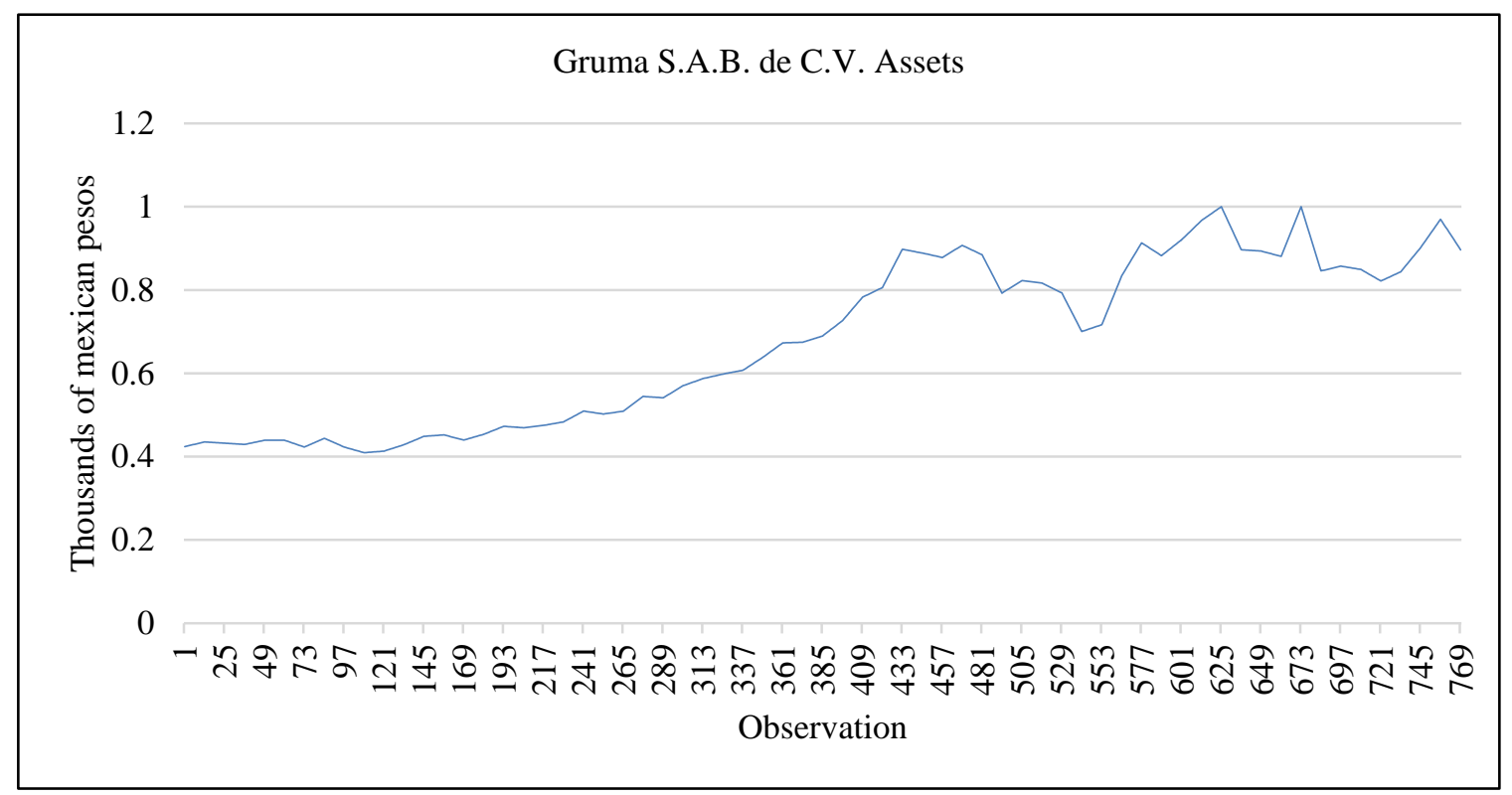

Figure 2. Linear interpolation of original data

Figure 2 shows the graph derived from the application of the function of linear interpolation to the original data, in order to expand observations about the database. 


\subsection{Fractal Interpolation}

Michael Barnsley (1988) proposed a function of fractal interpolation based on the theory of Iterated Functions Systems (IFS).

A data set is a set of points with the form $\left\{\left(X_{i}, F_{i}\right) \in R^{2}: i=0,1,2, \ldots, N\right\}$, where:

$$
\mathrm{X}_{0}<\mathrm{X}_{1}<\mathrm{X}_{2}<\mathrm{X}_{3}<\ldots<\mathrm{X}_{\mathrm{N}}
$$

An interpolation function corresponding to this data set is a continuous function $f:\left[X_{0}, X_{N}\right] \rightarrow \mathbb{R}$ such that:

$$
f\left(\mathrm{X}_{\mathrm{i}}\right)=\mathrm{F}_{\mathrm{i}} \text { for } \mathrm{i}=0,1,2, \ldots, \mathrm{N} \text {. }
$$

The points $\left(\mathrm{X}_{\mathrm{i}} \mathrm{F}_{\mathrm{i}}\right) \in \mathrm{R}^{2}$ are known as the points of interpolation. The function $f$ interpolates the data and (the graph of) $f$ passes through the points of interpolation.

For a data set, an IFS can be constructed in $\mathbb{R}^{2}$ in such a way that its attractor, which is designated as $\mathrm{G}$, is the graph of a continuous function $f:\left[\mathrm{X}_{0}, \mathrm{X}_{\mathrm{N}}\right] \rightarrow \mathbb{R}$ which interpolates the data.

An IFS with the form $\left\{\mathbb{R}^{2} ; \mathrm{w}_{\mathrm{n}}, \mathrm{n}=1,2, \ldots, \mathrm{N}\right\}$ is considered, where maps are transformations related to the special structure.

$$
w_{n}\left(\begin{array}{l}
x \\
y
\end{array}\right)=\left(\begin{array}{ll}
a_{n} & 0 \\
c_{n} & d_{n}
\end{array}\right)\left(\begin{array}{l}
x \\
y
\end{array}\right)+\left(\begin{array}{l}
e_{n} \\
f_{n}
\end{array}\right)
$$

Transformations are limited by the data in compliance with

$$
\mathrm{W}_{\mathrm{n}}\left(\begin{array}{c}
\mathrm{X}_{0} \\
\mathrm{~F}_{0}
\end{array}\right)=\left(\begin{array}{c}
\mathrm{X}_{\mathrm{n}-1} \\
\mathrm{~F}_{\mathrm{n}-1}
\end{array}\right) \text { and } \mathrm{W}_{\mathrm{n}}\left(\begin{array}{c}
\mathrm{X}_{0} \\
\mathrm{~F}_{0}
\end{array}\right)=\left(\begin{array}{c}
\mathrm{X}_{\mathrm{n}-1} \\
\mathrm{~F}_{\mathrm{n}-1}
\end{array}\right) \text { for } \mathrm{n}=1,2, \ldots \mathrm{N} \text {. }
$$

That is $n \in\{1,2,3, \ldots, N\}$. The transformation $w_{n}$ is specified by five real numbers $a_{n}, c_{n}, d_{n}, e_{n} y f_{n}$, which must comply with the four lineal equations

$$
\begin{gathered}
a_{n} X_{0}+e_{n}=X_{n-1} \\
a_{n} X_{N}+e_{n}=X_{n} \\
C_{n} X_{0}+d_{n} F_{0}+f_{n}=F_{n-1} \\
C_{n} X_{N}+d_{n} F_{N}+f_{n}=F_{n}
\end{gathered}
$$

There is a free parameter in each transformation: $d_{n}$, because the transformation $w_{n}$ is a limited transformation: it maps lines parallel to the axis of the ordinates in lines parallel to the axis of the ordinates. If $\mathrm{L}$ is a segment of line parallel to the axis of the ordinates, then $\mathrm{W}_{\mathrm{n}}(\mathrm{L})$ is also a segment of line parallel to the axis of the ordinates. The radius of length from $W_{n}(L)$ to the length of $L$ is $\left|d_{n}\right|$.

$d_{n}$ is known as the invariance factor of scale in the transformation $w_{n}$. Because $d_{n}$ is a free parameter, we can specify the scale invariance produced by the transformation. With $d_{n}=0, n=1,2, \ldots, N$, the linear interpolation function is retrieved in sections.

$d_{n}$ can be any real number. Equations for $\mathrm{a}_{\mathrm{n}}, \mathrm{c}_{\mathrm{n}}, \mathrm{e}_{\mathrm{n}} \mathrm{y} \mathrm{f}_{\mathrm{n}}$ can always be resolved in terms of data and $d_{n}$. In this way:

$$
\begin{gathered}
a_{n}=\frac{\left(X_{n}-X_{n-1}\right)}{\left(X_{n}-X_{0}\right)} \\
e_{n}=\frac{\left(X_{N} X_{n-1}-X_{0} X_{n}\right)}{\left(X_{N-} X_{0}\right)} \\
c_{n}=\frac{\left(F_{n}-F_{n}\right)}{\left(X_{N}-X_{0}\right)}-\frac{d_{n}\left(F_{N}-F_{0}\right)}{\left(X_{N}-X_{0}\right)} \\
f_{n}=\frac{\left(X_{N} F_{n-1}-X_{0} F_{n}\right)}{\left(X_{N}-X_{0}\right)}-d_{n} \frac{\left(X_{N} F_{0}-X_{0} F_{N}\right)}{\left(X_{N}-X_{0}\right)}
\end{gathered}
$$






Figure 3. Applying fractal interpolation to data

Figure 3 presents the time series graph for the extended database with values computed using the function of fractal interpolation. Notably, applying the function of fractal interpolation to a time series causes the magnitude of the unit of measurement of the independent variable to be lost.

\section{Results and Discussion}

The normality test performed on the data reveals that its probability distribution function does not adjust to a normal distribution, indicating the presence of fractality. When analyzing the results obtained from linear interpolation, it is apparent that the data calculated using this technique are generated from a straight line segment. Contrastingly, fractal interpolation generates data based on the behavior of the entire system that comprises the time series.

\section{Conclusions}

The irregular patterns in the financial time series of companies, as shown in this article, demonstrate that it is more appropriate to apply fractal methods to financial analysis. These differ from linear techniques, which do not consider irregular events and therefore do not adjust to these.

This is why the implementation of fractal interpolation is considered to be the innovative aspect of this study, as we verify that the fractal approach can be applied to the business context as it offers a better fit to the data representing financial information from these organizations.

\section{Acknowledgements}

The first author would like to thank the Instituto Tecnológico de Orizaba; Consejo Nacional de Ciencia y Tecnología (CONACYT) Beca Nacional for supporting postgraduate studies; CONACYT Beca Mixta for short research stay; the authors Romero Flores, Salazar Medina and Machorro Rodríguez thank the Coordination for Scientific Research, Academic Secretary, Technical Secretariat for Academic Exchange and Centro de Ciencias de la Atmósfera, (Center for Atmospheric Sciences), Universidad Nacional Autónoma de México, for their support to visiting professors.

\section{References}

Barnsley, M. F. (1988). Fractals everywhere. Boston: Academic Press.

Dai, M., Hou, J., \& Ye, D. (2016). Multifractal detrended fluctuation analysis based on fractal fitting: The long-range correlation detection method for highway volume data. Physica A: Statistical Mechanics and Its Applications, 444, 722-731. https://doi.org/10.1016/j.physa.2015.10.073

Li, L., \& Gao, J. (2014). Fractal geometry and the discussion on fractal interpolation. Journal of Pure and Applied Mathematics: Advances and Applications, 12, 105-118. 
Liu, X., Xia, J., Gunson, J., Wright, G., \& Arnold, L. (2014). Comparison of wave height interpolation with wavelet refined cubic spline and fractal methods. Ocean Engineering, 87, 136-150. https://doi.org/10.1016/j.oceaneng.2014.05.013

Mandelbrot, B. B. (1967). How long is the coast of Britain. Science, 156(3775), 636-638.

Mulligan, R. F. (2016). The multifractal character of capacity utilization over the business cycle: An application of Hurst signature analysis. The Quarterly Review of Economics and Finance. https://doi.org/10.1016/j.qref.2016.04.016

Serpa, C., \& Buescu, J. (2015). Explicitly defined fractal interpolation functions with variable parameters. Chaos, Solitons \& Fractals, 75, 76-83. https://doi.org/10.1016/j.chaos.2015.01.023

Spinadel, V. W. de. (2003). Geometría fractal y geometría euclidiana. Revista Educación y Pedagogía, XV(35), 85-91.

Torrés, J. M., \& Goís, C. W. de L. (2014). Organização fractal: um modelo e sugestões para gestão. Revista Ciências Administrativas ou Journal of Administrative Sciences, 17(3). Recovered from http://ojs.unifor.br/index.php/rca/article/view/3261

van Rensburg, A. (2014). Supporting business process design through a business fractal approach. South African Journal of Industrial Engineering, 25(1), 50-61. 